\title{
Retórica fotográfica y periodismo literario
}

\author{
Pilar IRALA HORTAL \\ Universidad de San Jorge \\ pirala@usj.es
}

Recibido: $15 / 11 / 2010$

Aceptado: 02/04/2011

\begin{abstract}
Resumen
La Periodística ha estudiado la relación entre el periodismo y la literatura, pero no ha reparado de forma suficiente en la fusión de la fotografía con el periodismo literario. La unión de ambos lenguajes, el visual y el escrito, refuerza la eficacia del mensaje periodístico ya que narra el mundo desde una mirada estética que profundiza en la realidad. Este estudio defiende que escritor y fotógrafo poseen ambos una amplia gama de herramientas retóricas para dar datos y dibujar contextos. Esta investigación describe, a través de las características del periodista literario que define KramER, algunas pautas esenciales compartidas por el Periodismo literario y el Fotoperiodismo, y concluye que sin el análisis de las fotografías que acompañan los relatos periodístico-literarios, el estudio de ese tipo de textos permanece incompleto.
\end{abstract}

Palabras clave: Fotografía, fotoperiodismo, literatura, periodismo, reportaje, retórica.

\section{Photographic Rhetoric and Literary Journalism}

\begin{abstract}
Specialized texts have studied the relationship between journalism and literature, but have not considered another important fusion: photography and literary journalism. The conjunction of these two text types, visual and written, particularly when both approach their subject from an aesthetic angle, increases journalistic efficiency. In the same way that a writer uses a series of linguistic resources to construct text, the photographer uses techniques to do the same. KrAMER describes the characteristics of literary journalism and we will consider whether it is possible to adapt these features to photojournalism. The present paper describes some prime guidelines that literary journalism shares with photojournalism, and highlights the fact that without photographic analysis of the images in literary journalistic texts, the study of this kind of story is incomplete.
\end{abstract}

Key words: Photography, Photojournalism, Journalism, Literature, Rethoric, Story.

\section{Referencia normalizada}

IRALA HORTAL, Pilar (2011): "Retórica fotográfica y periodismo literario". Estudios sobre el mensaje periodístico. Vol. 17, núm. 1, págs.: 57-65. Madrid, Servicio de Publicaciones de la Universidad Complutense.

Sumario: 1. Relación entre periodismo y fotografía. 2. Función de la fotografía en el periodismo. 3. Los recursos de la fotografía aplicados al periodismo literario. 4. Periodismo literario y fotografía documental: rasgos de Kramer en las fotos de "Vidas al límite". 5. Conclusiones. 6. Referencias biblográficas.

\section{Relación entre periodismo y fotografía}

Los estudiosos de la relación entre periodismo y literatura han ahondado en el análisis de los textos, desde los recursos expresivos lingüísticos hasta a los rudimentos del reporterismo. Sin embargo, la investigación periodístico-literaria casi no ha tenido en cuenta otra relación producida en la prensa (diarios y revistas, tanto en papel como digitales): la unión entre los textos periodísticos literarios nacidos del reporterismo con la fotografía. Como bien dicen los viejos editores de 
periódicos, sin una buena foto no hay reportaje; no se publica una crónica; no tiene sentido un perfil. Así, las principales revistas de periodismo literario dedican tanto o más espacio a la imagen que al texto. La narración visual es complemento de la narración textual. Una imagen sin palabras que expliquen y anclen el mensaje visual puede no valer nada.

En síntesis, algunos géneros del periodismo literario necesitan del fotoperiodismo. Sin embargo, esta fusión tan fructífera para la transmisión del mensaje se rompe cuando llega el momento de publicar esas historias en antologías. Después de la vida en común en diarios y revistas, cada lenguaje (textual y visual) se separa, y los textos son publicados como libros sin imágenes; y las fotografías como fotolibros o expuestas en galerías y museos, separados siempre de los textos que complementaban y cerraban el círculo de eficacia comunicativa.

Las causas de la disociación de texto e imagen son variadas: de un lado, los elevados costes de edición de un libro antológico acompañado de fotografías de buena calidad; de otro, la reticencia a colocar en las exposiciones demasiado texto para el visitante, entre otras cuestiones. Las siguientes páginas se proponen describir con un ejemplo la utilidad de estudiar los textos junto con las imágenes que enriquecieron el mensaje periodístico original. Si tomamos como buena la frase: cada texto tiene su contexto, el contenido visual es imprescindible para el análisis de las composiciones periodístico-literarias. El fotoperiodismo es eso: periodismo con imágenes, un periodismo que, en el caso aquí tratado es, además, estética, es decir, literatura. Y la literatura, desde tiempos inmemoriales, tampoco se explica sin imágenes, ni retóricas ni gráficas.

Que la fotografía es fundamental hoy en la prensa es algo ya asumido por productores -medios de comunicación- y receptores. Tanto en los medios escritos como en los periódicos digitales el contenido visual ha adquirido en los últimos años un protagonismo que ha llevado a la mayoría de ellos a tener secciones específicas dedicadas a la imagen tales como Foto del día, en El País ${ }^{1}$; Day in Pictures, en la BBC News ${ }^{2}$ o Day in Photos, en el Washington Post ${ }^{3}$.

En el transcurso de esta investigación se han analizado tres reportajes y sus respectivas fotografías ${ }^{4}$. En las páginas de este trabajo se vuelcan las conclusiones del estudio de las imágenes publicadas en un reportaje literario escrito por Juan José Millás para El País dSemanal, revista gráfica muy leída en España distribuida con el periódico El País. El ejemplo resultó seleccionado a partir de una criba de los años 2007, 2008 y 2009 de dicha publicación. En este ejemplo examino las fotografías de Daniel Sánchez-Alonso en el contexto del reportaje de Millás, y

\footnotetext{
${ }^{1}$ http://www.elpais.com/fotografia/

${ }^{2}$ http://news.bbc.co.uk/2/hi/in_pictures/default.stm

${ }^{3}$ http://www.washingtonpost.com/

${ }^{4}$ Además del texto de Juan José MiLlás que he analizado en este estudio, se estudiaron también: ArIZA, Luis Miguel (2007). “¿En qué cree el ser humano?”. El País Semanal, 9/12/2007, no 1628, pp. 64-83 y CARLIN, John (2008). “Malaria, la batalla decisiva”. El País Semanal, 20/01/2008, nº 1634, pp. 40-53.
} 
analizo cómo estas imágenes complementan al texto periodístico literario, demostrando así su importancia en el contexto de la noticia. Para el análisis utilizo la descripción de algunos procedimientos del periodismo literario según Mark KRAMER (2001).

\section{Función de la fotografía en el periodismo}

La imagen fotográfica en el periodismo literario, igual que en la prensa en general, debe reforzar el mensaje, en el mejor de los casos, si la fotografía es pensada con tanto cuidado como el texto. Sucede que esto no ocurre con la suficiente frecuencia y es común que las imágenes sean, las más veces, sólo ilustrativas. Un reportaje tendrá mayor impacto, interés y eficacia en la transmisión de su mensaje cuanta más relación exista entre el mensaje textual y visual. Cuando se cumple esta imbricación, las técnicas lingüísticas propias del periodismo literario encontrarán su réplica en los recursos visuales, en los planos, la luz y color o blanco y negro, cuyo uso estético subrayarán el contenido, pero también se sumarán a los medios retóricos de la escritura, consiguiendo así dotar al reportaje de una entidad de mayor profundidad. Esta simbiosis crea una unión periodística cuyas ideas aparecen reforzadas, a través de ambos lenguajes.

Para llevar a cabo el análisis de un caso en el que se da esta alianza he tenido en cuenta la descripción de Lorenzo VILCHEs (1987: 71) respecto a las características del fotoperiodismo, y he analizado las imágenes a la luz de los siguientes planteamientos:

a) Su estructura es compleja y, al igual que el texto, necesita de un aprendizaje de lectura. En este sentido, Rafael Gómez Alonso (2005: 6), cuando se refiere al significado que una fotografía tiene, afirma que para en su lectura y comprensión intervienen varios factores entre ellos los sociológicos o los símbolos convencionales o accidentales, de tal forma que el lector necesita unas herramientas culturales y conceptuales que le ayuden en la decodificación del texto fotográfico.

b) No es ilustración ni mero acompañamiento del texto, pero por supuesto, tampoco es su sustitución;

c) Es extraordinariamente útil en determinados momentos del discurso, especialmente en lo que se refiere a la identificación y reconocimiento;

d) Al igual que el texto, la fotografía en los medios de comunicación también puede alcanzar altas cotas de simbolismo y subjetivismo. Rafael GómEz Alonso (2005: 4) aclara dónde se encuentra la retórica en la fotografía para alcanzar significados profundos y explica cómo los fenómenos de denotación, designación y connotación conforman tales expresiones.

e) Texto e imagen se trabajan juntos en el reportaje para dar un contenido común enriquecido y de mayor eficacia que la presentación de la información textual y gráfica por separado.

\section{Los recursos de la fotografía aplicados al periodismo literario}

El fotógrafo, como el periodista, cuenta con una serie de herramientas para construir su 
mensaje, reforzar, matizar o desmentir datos. Entre los recursos más importantes se encuentra la composición, que distribuye los elementos dentro del encuadre, a la manera del escritor cuando elige los datos de trabajo. En este recurso es muy importante el uso de los ángulos ya que son los puntos de vista donde se sitúa el narrador.

Otro recurso determinante es la luz. La iluminación de la escena desencadena una serie de procesos cognoscitivos, no siempre conscientes, que hacen funcionar, o no, una imagen, su simbolismo y connotaciones. Y no sólo la luz es importante en el aspecto estético, sino también en el informativo-literario, porque matiza de una forma retórica la escena, el contexto. Puede ser descriptiva o simbólica y aportar significados más allá de la lectura superficial tales como la soledad, aislamiento, esperanza, etc. Este uso de la luz es comparable a las descripciones intimistas en el periodismo narrativo.

Por último, el uso del color o del blanco y negro define el estilo del escritor: más realista (color) o documental y sugestivo (blanco y negro), y es responsable en gran medida de la forma de llegar al lector el texto y la imagen. Se opta por el blanco y negro cuando se busca crear un ambiente documental o intimista, es decir, un aura, tal y como defendía Susan SonTAg (1977). Este halo otorga sensación de distancia histórica, de pasado, cuya presencia amortigua en cierta forma el dolor mostrado 5 . Del mismo modo, el escritor utiliza descripciones más documentales o más narrativas. El color da a la escena un carácter más realista y descriptivo.

Composición, angulación, luz, color o escala de grises son recursos que permiten al fotógrafo contar de un modo personal y retórico su relato. De igual forma, el periodista literario construye con las herramientas de la literatura su historia. Muchos son los puntos en común entre ambos lenguajes y evidente su complementariedad.

Como vemos, la fotografía cuenta con sus propios recursos, sus giros y sus figuras aplicándolas con la misma finalidad que el periodismo narrativo. Este trabajo utiliza la descripción de los rasgos descriptivos del periodismo literario y lo aplica a las fotografías del reportaje de Juan José Millás, Vidas al límite. Con este método quiero plantear la existencia de un "fotoperiodismo literario" como fórmula de adscripción genérica y subgénero dentro de las diferentes relaciones que se establecen entre el Periodismo y la Literatura ${ }^{6}$. El procedimiento usado se ancla en las Reglas quebrantables para periodistas literarios de Mark KRAMER (2001: 7385). Aunque este autor se refiere exclusivamente a los textos, he extrapolado su descripción desde el punto de vista de la imagen para leer "fotoperiodista" en lugar de "periodista literario":

- Se interna en el mundo de sus personajes y en la investigación sobre su contexto.

${ }^{5}$ Esta idea se recoge en varios de los artículos recopilados en el libro de Susan SonTAG On Photography, publicado en 1977 y hoy traducido a varios idiomas y con varias ediciones.

${ }^{6}$ Esta propuesta de trabajo es fruto de las investigaciones realizadas junto al profesor Jorge RoDRÍGUEZ, especialista en Periodismo literario, y con quien la autora ha escrito diferentes estudios en esta línea. 
- Desarrolla compromisos implícitos de fidelidad y franqueza con sus lectores y fuentes.

- Escribe principalmente sobre hechos comunes y corrientes.

- Escribe con una "voz intimista" que resulta informal, franca, humana e irónica.

- Escribe desde una posición móvil, desde la cual puede relatar historias y dirigirse a los lectores.

- La estructura cuenta, como una mezcla de narración primaria con historias y digresiones que amplifican y encuadran los sucesos.

- Desarrolla el significado al construir sobre las reacciones del lector.

\section{Periodismo literario y fotografía documental: rasgos de Kramer en las fotografías de "Vidas al límite"}

Bajo el título "Vidas al límite" se podrían narrar algunos días en la vida de un enfermo terminal, las aventuras de un pescador en el Gran Sol, o las experiencias de un grupo de voluntarios en los confines del mundo. Sin embargo, este reportaje de Juan José MiLlás describe el trabajo en un laboratorio genético. Millás se centra en dos moscas del recinto a las que personifica bajo los nombres de Catalina y Pruden. La humanización de los insectos y el estilo narrativo que se desprende de dicho recurso literario permite que los temas científicos tratados sean más accesibles al espectador. Introduce el acercamiento emocional a estos individuos de laboratorio y explica su ciclo biológico a través de una relación, a veces metafórica otras real, con ellos.

Estos recursos lingüísticos sirven también para que la fotografía use recursos similares a pesar de que las imágenes del reportaje compartan el carácter científico del texto. Hago esta puntualización porque es importante tener en cuenta que algunas cuestiones no son fáciles de ser abordadas desde un punto de vista estético, por ejemplo las moscas de un laboratorio. El fotógrafo de este trabajo, Daniel SÁnCHEZ-Alonso, resuelve bien este tema. Es especialista en retrato y vuelca su experiencia en este género a través de primeros planos y composiciones a doble página como veremos más adelante.

A continuación expongo los rasgos del periodista literario de Kramer que podemos leer desde el punto de vista del fotógrafo literario:

Los periodistas literarios [los fotógrafos literarios] se internan en el mundo de sus personajes y en la investigación sobre su contexto.

El primer elemento de conexión entre el periodista literario y el fotógrafo es la necesidad de una inmersión, KRAMER (2001: 74): un conocimiento profundo, conseguido con la investigación exhaustiva de la realidad, la presencia examinadora del escritor o fotógrafo en el lugar de la noticia, y una convivencia con el entorno (persona o comunidad) del tema. No sólo se trata de estudiar el hecho, sino vivirlo, viajar a los escenarios, seguir el rastro, mimetizarse con el entorno, en definitiva.

En este reportaje SÁNCHEZ-Alonso se ha metido en el laboratorio y se ha acercado a Catalina y Pruden y a sus vidas. Abundan los primeros planos, a modo de retrato. Este recurso permite acercarnos a los protagonistas y conocerlos mejor. 
Vemos su casa, las probetas; a sus caseros, los científicos y su vida íntima. Todo lo rastrea el fotógrafo para mostrarnos el contexto completo de esta historia de amor y genética. Ayudado por el relato, SÁnCHEZ-AlONSo hace un zoom sobre la existencia de estos insectos. El plano corto es emocional porque permite al espectador asomarse a las reacciones más íntimas de los retratados, del mismo modo que el texto utiliza metáforas que humanizan y nos acercan a los insectos.

Los periodistas literarios [los fotógrafos literarios] desarrollan compromisos implícitos de fidelidad y franqueza con sus lectores y sus fuentes.

KRAMER se refiere con este rasgo a que el periodista, el fotógrafo para nosotros, no debe alterar la realidad. En "Vidas al límite" las imágenes de Catalina y Pruden están tomadas con un microscopio, o son primeros planos de las cubetas donde viven, o son los propios científicos trabajando en el laboratorio. En este sentido, se cumple la no manipulación de la realidad. Sólo se refleja la cotidianidad de la jornada de trabajo. SÁnchez-Alonso no sólo muestra una parte de la noticia, el laboratorio, más fácil de observar para el lector, sino también a las moscas con la franqueza del plano más corto.

Los periodistas literarios [los fotógrafos literarios] escriben principalmente sobre hechos comunes y corrientes.

Para hablar de grandes eventos o situaciones fuera de lo común (guerras, enfermedades, desplazamiento masivo de personas,...) el periodista se centra en un caso: una persona o familia; busca la identificación. Así, se presenta lo particular como sinécdoque de lo general, la parte por el todo. A menudo, a través de esta historia concreta se busca presentar una cuestión de mayores dimensiones e interés humano.

El texto de MiLlás se centra en contar el testimonio de dos moscas, descritas a través de reacciones y rasgos humanos. Catalina y Pruden son aquí esos seres comunes que cuentan una historia más allá de ellos mismos: es la fábula de su amor, pero también de su entrega a la ciencia, puesto que estas moscas son transformadas genéticamente en busca de respuestas para la mejora de la calidad de vida del ser humano.

En este sentido, las fotografías del artículo son primeros planos y cuerpo entero de los protagonistas. Se muestran los rasgos -comunes y personales- de las moscas, tal y como hace el retrato. Se presentan a los protagonistas, cómo son, cómo evolucionan, qué les pasa, y todo ello tiene su reflejo en las fotografías: el rostro de Catalina; Catalina y Pruden en su casa (su probeta); los padres de los dos (los científicos en el laboratorio); Catalina paseándose por las paredes de su edificio; dando a luz (poniendo un huevo); Pruden cortejando a Catalina. Es decir, todo un reportaje gráfico de la vida de estos dos amantes.

Los periodistas literarios [los fotógrafos literarios] escriben con una "voz intimista”, que resulta informal, franca, humana e irónica.

Es la mirada que el escritor, o fotógrafo, lanza sobre el tema. Puede ser despiadada, cruel, irónica... Es la forma que tiene el autor (del texto o de la imagen) de ver una realidad concreta. En "Vidas al límite" la mirada fotográfica es científica. 
Las imágenes no presentan una estética tierna, ya que el tema no lo propicia. La percepción intimista y emotiva que generan unas imágenes tan asépticas a priori es consecuencia del estilo literario de MıLLÁs, lo que demuestra la unión y el trasvase de sentidos entre el lenguaje visual y textual. Con sus descripciones humanizadas consigue que cuando vemos a Catalina poner un huevo, como el resto de los millones de moscas del mundo, el lector pueda sentir cierta ternura, por la madurez del individuo, aunque lo contemplado sea una mosca común desconocida dos párrafos atrás.

El texto completa a la imagen y, a su vez, esta aporta una determinada clave de identificación de los individuos, a veces cruel, otras tierna.

Los periodistas literarios [los fotógrafos literarios] escriben desde una posición móvil, desde la cual pueden relatar historias y dirigirse a los lectores.

La posición móvil se puede trasladar al uso de los planos y ángulos en fotografía. El punto de vista se aleja o se acerca dependiendo de ellos, desde el gran plano general hasta el plano detalle, y desde la vista cenital o picada al contrapicado.

El fotógrafo cuenta la historia con los recursos visuales más adecuados para la transmisión efectiva del mensaje. En este reportaje, dado su especial carácter científico y el pequeño tamaño de los protagonistas, el uso de las herramientas visuales está limitado a la elección del color para las imágenes, y la apertura de los planos, usando los más cercanos para las moscas y de tres cuartos o de conjunto para los científicos.

El plano de tres cuartos o americano es narrativo y emocional: nos muestra la acción del retratado con algunos detalles personales dada su cercanía. El plano de conjunto es narrativo y descriptivo porque nos enseña el contexto en el que se desarrolla la acción, en este caso, el entorno del laboratorio. Se comprueba la posición móvil del fotógrafo en el uso de estos diferentes planos.

SÁnchEZ-Alonso no puede usar picados o contrapicados, ángulos difíciles o contrastes ya que las imágenes deben adaptarse a las condiciones del contexto, en este caso al tema y al pequeño recinto científico y más concretamente, mosquil.

La estructura cuenta, como una mezcla de narración primaria con historias y digresiones que amplifican y encuadran los sucesos.

La estructura debe entenderse desde un doble punto de vista: interna y externa. La estructura interna se refiere a la composición de la foto, es decir, al orden de los elementos dentro del encuadre. La estructura externa conecta con el diseño y la colocación de la imagen dentro del texto, incluso el orden de las fotografías y cómo aparecen relacionadas de forma gráfica con la parte escrita y con los márgenes físicos de las páginas. Todos son recursos que el lector tiene en cuenta, en ocasiones de modo subconsciente.

"Vidas al límite" se presenta en siete unidades visuales, contando la portada del suplemento. Dos de las páginas que contienen imágenes son dobles, otras dos a cara completa (sin contar la portada) y dos más con sendas imágenes pequeñas.

El recurso de usar dobles páginas con Catalina y Pruden, o páginas completas con el rostro o perfil de la mosca femenina aporta los recursos necesarios para 
conseguir la identificación con los sujetos, invita a conocer su mundo de una manera más cercana, e incluso a sus padres científicos, presentados en pequeñas imágenes en el centro del texto. De este modo, la estructura externa ayuda a leer los recursos utilizados en la estructura interna y facilita su lectura y comprensión.

Los periodistas literarios [los fotógrafos literarios] desarrollan el significado al construir sobre las reacciones del lector

Tanto escritor como fotógrafo usan los recursos a su alcance buscando una determinada respuesta en el lector. Además, en muchas ocasiones la primera aproximación de éste al artículo (a veces la única) es a través de la imagen y de los titulares. Así, el fotógrafo toma y selecciona las fotografías en función de la reacción que desea. Por su parte, el editor hace una nueva discriminación de las imágenes y el maquetador las contextualiza, dotando de mayor o menor impacto o interés a la composición del conjunto.

En este caso, Catalina y Pruden se pasean por las páginas de El País Semanal y muestran sus grandísimos ojos rojos y su abdomen transparente sin pudor. Antes de leer el reportaje eran dos moscas, tan pegajosas como el resto de sus familiares. Pero ahora, son Catalina y Pruden, conocemos su vida, sus amores y su muerte. Si no estuvieran situadas en el contexto de su historia de amor, podrían haber sido rechazables visualmente. Sin embargo, imágenes como la danza de apareamiento mostrada en una de las páginas dobles plantean dos posibilidades de acercamiento: la visión microscópica de dos moscas de la fruta, incómodas y sucias en las jornadas de verano; o la identificación de un momento romántico cuando dos protagonistas se miran fijamente a los ojos y parecen suspirar de amor. La lectura en una u otra clave se encuentra en la unión del texto de MiLlás y el tratamiento fotográfico de SÁnCHEZ-Alonso. Estas dos posturas, la científica y la romántica (retórica y literaria), se convierten en una sola gracias al texto que ahorma la imagen.

\section{Conclusiones}

Como he comentado en la introducción, la unión del periodismo literario con la fotografía es efímera. Los libros recopilatorios de los textos no incluyen imágenes y, en ocasiones, cuando lo hacen suelen ser pequeñas o con muy poca calidad. Un ejemplo de este hecho es el libro de Manuel Rivas El periodismo es un cuento que contiene algunos de sus reportajes literarios en El País.

Las imágenes, o bien forman parte de una serie independiente del texto y los derechos de reproducción son comprados por el medio donde se publicará el reportaje; o bien, pasada la publicación se exponen en galerías y centros de arte, huérfanos del texto al que complementaban. Un ejemplo de ambas situaciones es la serie The Gift, de Giorgia FionINo, que está siendo expuesta en toda Europa y cuyas imágenes aparecieron en el reportaje de El País, de Luis Miguel ARIZA, titulado “¿En qué cree el ser humano?”.

Considero importante para la transmisión íntegra del mensaje periodísticoliterario la publicación de los textos junto a las fotografías que los acompañan cuando aparecen en la prensa. Sin embargo, las imágenes suelen obviarse cuando estos textos se agrupan en libros y demás compilaciones. Una solución para esta 
circunstancia es el medio digital. Este es un buen soporte para apreciar ambos 'relatos' (textual y visual) en su contexto original, ya que la fotografía, con sus recursos visuales, sus luces y sombras, sus blancos y negros que son las metáforas del periodismo literario, en adecuado convenio, crean un texto narrativo y estético a la vez, intimista, que profundiza en temas de interés humano, y ahonda en la noticia de una manera personal y única. En definitiva indisoluble.

\section{Referencias bibliográficas}

ARIZA, Luis Miguel (2007): “¿En qué cree el ser humano?” El País Semanal, 9 de diciembre, $\mathrm{n}^{\circ} 1628$, pp. 64-83.

CARLIN, John (2008): “Malaria, la batalla decisiva. El País Semanal”, 20 de enero, $\mathrm{n}^{\circ} 1634$, pp. 40-53.

GÓMEZ ALONSO, Rafael (2005): "Retórica fotográfica. Ingenio y provocación”. Revista ICONO 14, $\mathrm{n}^{\circ} 5$.

KRAMER, Mark (2001): "Reglas quebrantables para periodistas literarios". Elmalpensante, $\mathrm{n}^{\circ}$ 32, pp. 73-85.

MILLÁS, Juan José (2008): "Vidas al límite”. El País Semanal, 3 de agosto, no 1662, pp. 32-43.

RIVAS, Manuel (1997): El periodismo es un cuento. Madrid, Alfaguara.

RODRÍGUEZ RODRÍGUEZ, Jorge Miguel (2007a) "Entrevista a Fernando López Pan”. Nuestro tiempo, abril, $\mathrm{n}^{\circ}$ 634, pp. 33-42.

- (2007b) Aproximación a las relaciones entre periodismo y literatura en España: del discurso de Joaquín F. Pacheco en la Real Academia (1845) hasta "Géneros periodísticos” de Martín Vivaldi (1973) (tesis doctoral). Pamplona, Universidad de Navarra.

SONTAG, Susan (1996): Sobre la fotografía. Barcelona, Edhasa.

VILCHES, Lorenzo (1987): Teoría de la imagen periodística. Barcelona, Paidós. 